\title{
Reduction of temperature in silicon photovoltaic module using thermal radiation coating
}

\author{
Satoshi Nakamura ${ }^{1}$ and Kensuke Nishioka ${ }^{1, a}$ \\ ${ }^{1}$ Faculty of Engineering, University of Miyazaki, 1-1 Gakuen Kibanadai Nishi Miyazaki 889-2192, Japan
}

\begin{abstract}
The temperature of solar cells increases under the actual operating conditions, and the conversion efficiency of solar cells decreases with increasing temperature. In this study, a thermal radiation layer was coated on the back sheet of the PV module by a spray coating method and the effect was evaluated. The thickness of the layer was $30 \mu \mathrm{m}$. The temperature of the PV module with the thermal radiation coating was lower than that of the PV module without the thermal radiation coating. And the operating temperature range of the PV module with the thermal radiation coating was decreased by $2 \sim 3^{\circ} \mathrm{C}$. The open-circuit voltage of the PV module with the thermal radiation coating was $0.1 \mathrm{~V}$ higher than that of the module without the coating due to the thermal radiation coating.
\end{abstract}

\section{Introduction}

Photovoltaic (PV) power generation is becoming widespread as a clean and gentle energy source for the earth. Though the performance of solar cell is mainly evaluated under the standard test condition (STC: $1 \mathrm{~kW} / \mathrm{m}^{2}$ irradiation, $25^{\circ} \mathrm{C}$ module temperature, and AM1.5 global spectrum), operation under various environments is required for PV systems, and environmental factors such as solar irradiation and module temperature seriously influence the generating performance of the systems

The temperature of solar cells increases under the actual operating conditions, and the conversion efficiency of solar cells decreases with increasing temperature [111]. It is therefore very important to reduce the cell temperature in PV modules.

In this study, a thermal radiation layer was coated on the back sheet of a PV module and the effect was evaluated.

\section{Experimental procedure}

Figure 1 shows the single crystalline silicon PV modules (area: $1200 \mathrm{~mm} \times 527 \mathrm{~mm}$ ) evaluated in this study. The output characteristics of PV modules with and without thermal radiation coating were compared. A thermal radiation layer (Pelcool (R), PELNOX Ltd.) was coated on the back sheet of the PV module by a spray coating method. The thickness of the layer was $30 \mu \mathrm{m}$. The thermal radiation layer consisted of acrylate resin and inorganic fillers. The fillers were selected to radiate the heat, particularly in the temperature range from 40 to $100^{\circ} \mathrm{C}$, which is the main range of operating temperature

\footnotetext{
nishioka@cc.miyazaki-u.ac.jp
}

for the PV module. The thermal emissivity of the layer is 0.95. In order to detect the temperature of the PV module $\left(\mathrm{T}_{\mathrm{mod}}\right)$, temperature sensors (Pt100) were set on the back surface of the PV modules. The current-voltage (I-V) characteristics were measured using an I-V curve tracer (MP-160, EKO). The modules with and without the thermal radiation coating were evaluated at University of Miyazaki (Miyazaki, Japan).

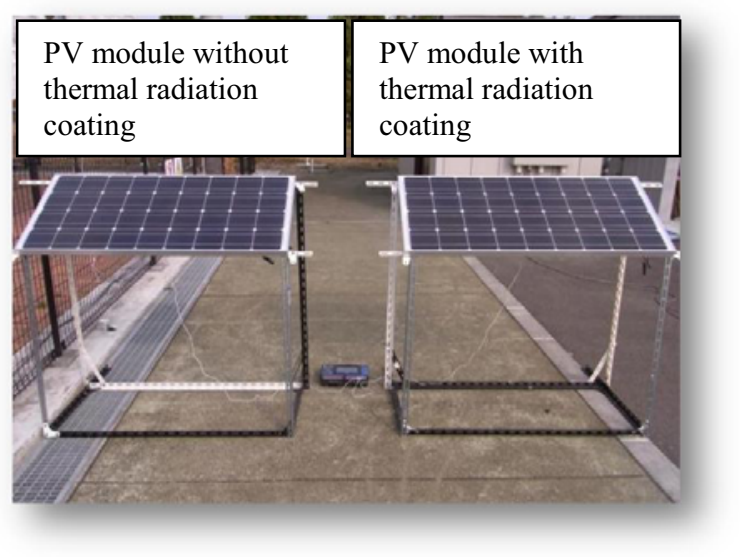

Figure 1. Single crystalline silicon PV modules (area: $1200 \mathrm{~mm}$ $\times 527 \mathrm{~mm}$ ) evaluated in this study.

\section{Results and discussion}

Figure 2 shows the temperatures of the PV modules $\left(\mathrm{T}_{\text {mod }}\right)$ with and without thermal radiation coating. Figure 2 also shows the ambient temperature. The ambient temperature was stable during the measurement period. The temperature of the PV module with the thermal radiation coating was lower than that of the PV module 
without the thermal radiation coating. The effect of the high-radiation layer was remarkable.

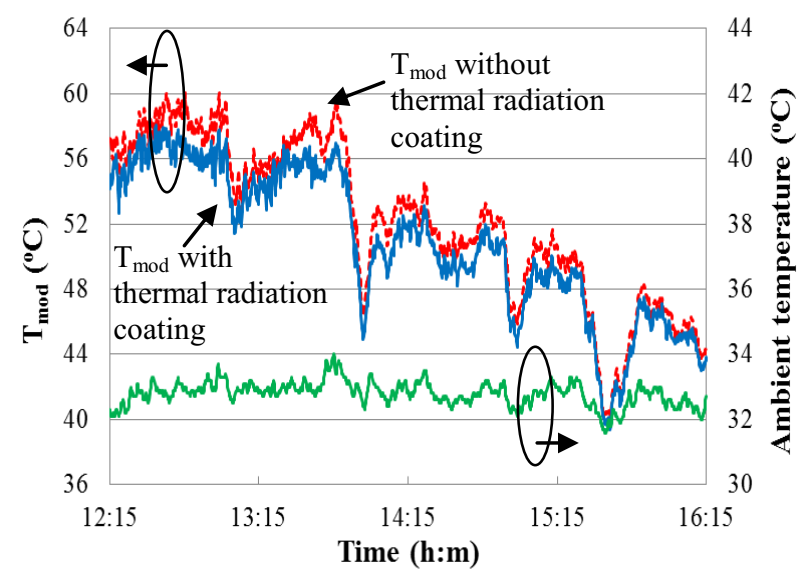

Figure 2. Temperatures of the PV modules with and without thermal radiation coating.

Figure 3 shows the $\mathrm{T}_{\text {mod }}$ of the PV module without the thermal radiation coating and the difference in temperature between $\mathrm{T}_{\text {mod }}$ of the $\mathrm{PV}$ modules with and without thermal radiation coating ( $\mathrm{T}_{\bmod }$ without coating $\mathrm{T}_{\text {mod }}$ with coating). The maximum difference of $3.38^{\circ} \mathrm{C}$ was observed at 12:57. It is found that the difference in temperature between $\mathrm{T}_{\text {mod }}$ of the PV modules with and without thermal radiation coating increases with increasing $\mathrm{T}_{\text {mod }}$ of the $\mathrm{PV}$ module without thermal radiation coating.
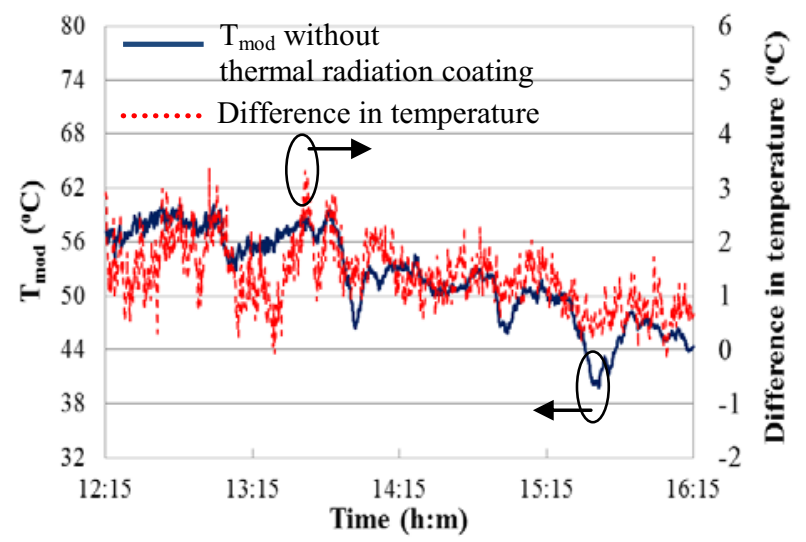

Figure 3. $\mathrm{T}_{\bmod }$ of the $\mathrm{PV}$ module without thermal radiation coating and the difference in temperature between $\mathrm{T}_{\bmod }$ of the $\mathrm{PV}$ modules with and without thermal radiation coating.

When we define a backside of PV module [area: $A_{1}$ $\left(\mathrm{m}^{2}\right)$, emissivity: $\varepsilon_{1}$ ] and an environment [area: infinite], the radiation heat from the backside of PV module to the environment $Q_{12}(\mathrm{~W})$ is given by

$$
Q_{12}=A_{1} \varepsilon_{1} \sigma\left(T_{1}^{4}-T_{2}^{4}\right)
$$

where $\sigma, T_{1}$, and $T_{2}$ are the Stefan-Boltzmann constant $\left(5.67 \times 10-8 \mathrm{~W} / \mathrm{m}^{2} \cdot \mathrm{K}^{4}\right)$, the absolute temperature $(\mathrm{K})$ of the PV module, and the absolute temperature $(\mathrm{K})$ of the environment, respectively. It was found that the radiation heat increased with increasing emissivity, and the high emissivity of the thermal radiation layer enhanced the heat radiation from the module to the environment. $Q_{12}$ (W) is higher when $T_{1}$ is higher. Therefore, the difference in temperature between $\mathrm{T}_{\text {mod }}$ of the PV modules with and without thermal radiation coating increased with increasing $\mathrm{T}_{\text {mod }}$ of the PV module without thermal radiation coating.

Figure 4 shows the open-circuit voltage $\left(\mathrm{V}_{\mathrm{oc}}\right)$ of the PV modules with and without the thermal radiation coating. $\mathrm{V}_{\mathrm{oc}}$ of the PV module with the thermal radiation coating was $0.1 \mathrm{~V}$ higher than that of the module without the coating during the test period. The $\mathrm{V}_{\mathrm{oc}}$ of $\mathrm{PV}$ modules decreases with increasing temperature.

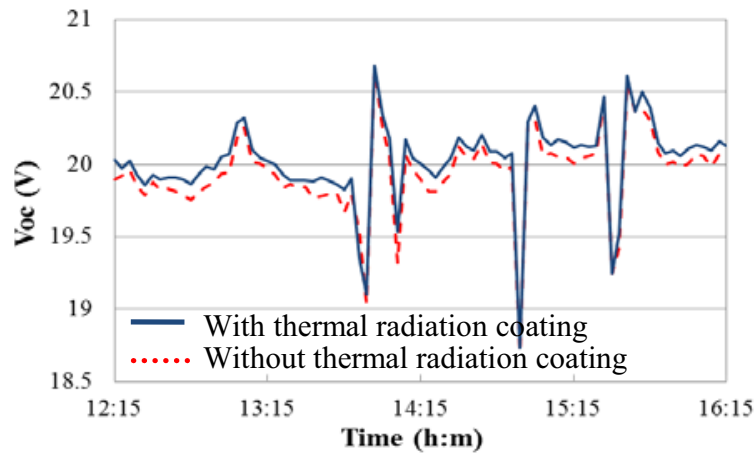

Figure 4. Open-circuit voltage $\left(\mathrm{V}_{\mathrm{oc}}\right)$ of the $\mathrm{PV}$ modules with and without the thermal radiation coating.

The I-V characteristics of the solar cell are expressed by

$$
I=I_{0}\left\{\exp \left(\begin{array}{c}
q V \\
n_{D} k T
\end{array}\right)-1\right\}-I_{s c},
$$

where $I_{\mathrm{sc}}, I_{0}, q, n_{\mathrm{D}}, k$, and $T$ are the short-circuit current, saturation current, elementary charge, diode ideality factor, Boltzmann constant, and absolute temperature, respectively [12].

From Eq. (2), $\mathrm{V}_{\mathrm{oc}}(I=0)$ is given by

$$
V_{o c}=\frac{n_{D} k T}{q} \ln \left(\begin{array}{l}
I_{s c} \\
I_{0}
\end{array}\right)
$$

From Eq. (3), the temperature characteristic of saturation current $\left(I_{0}\right)$ markedly influences the temperature 
characteristic of $\mathrm{V}_{\mathrm{oc}}$. The saturation current density $\left(J_{0}\right)$ is given by

$$
J_{0}=q n_{i}^{2}\left(\frac{D_{e}}{N_{A} W_{p}}+\frac{D_{h}}{N_{D} W_{n}}\right)
$$

where $n_{\mathrm{i}}$ is the intrinsic carrier concentration, $N_{\mathrm{A}}$ and $N_{\mathrm{D}}$ are the acceptor and donor concentrations, respectively, $W_{\mathrm{p}}$ and $W_{\mathrm{n}}$ are the thicknesses of the $p$ and $n$ neutral regions, respectively, and $D_{\mathrm{e}}$ and $D_{\mathrm{h}}$ are the diffusion constants of electrons and holes, respectively [13]. $J_{0}$ strongly depends on $T$ through its proportionality to the square of $n_{\mathrm{i}}$, which is expressed by

$$
n_{i}^{2}=4 M_{c} M_{v}\left(2 \pi k T / h^{2}\right)^{3}\left(m_{e}^{*} m_{h}^{*}\right)^{3 / 2} \exp \left(-E_{g} / k T\right),
$$

where $M_{\mathrm{c}}$ and $M_{\mathrm{v}}$ are the number of equivalent minima in the conduction and valence bands, respectively, $h$ is Planck's constant, and $m_{\mathrm{e}}{ }^{*}$ and $m_{\mathrm{h}}{ }^{*}$ are the effective masses of electrons and holes, respectively [14].

From Eqs. (3)-(5), it is found that the decrease in $\mathrm{V}_{\mathrm{oc}}$ with increasing temperature arises mainly from the change in $n_{\mathrm{i}}$. The value of $J_{0}$ increases exponentially with decreasing $1 / \mathrm{T}$, and $\mathrm{V}_{\text {oc }}$ decreases linearly with increasing T.

$\mathrm{V}_{\mathrm{oc}}$ of the PV module with the thermal radiation coating was higher due to the cooling effect of the thermal radiation coating.

Figure 5 shows the conversion efficiency of the PV modules with and without the thermal radiation coating. The conversion efficiency decreased linearly with increasing temperature. The data for the PV module with the thermal radiation coating existed in the low temperature range owing to the heat-release effect of the coating. As shown in Fig. 3, the cell temperature of the $\mathrm{PV}$ module with the thermal radiation coating was $2 \sim 3^{\circ} \mathrm{C}$ lower than that of the module without thermal radiation coating. Eventually, the temperature range of the PV module with the thermal radiation coating was decreased by $2 \sim 3^{\circ} \mathrm{C}$.

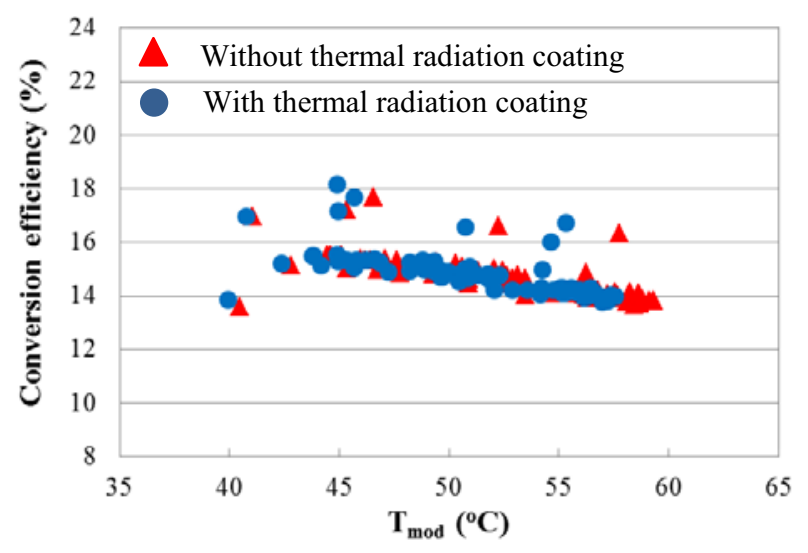

Figure 5. Conversion efficiency of the PV modules with and without the thermal radiation coating.
A high-efficiency PV module can be achieved with a combination of cell and module technologies. In this study, a new simple coating technology for handling heat radiation was developed. By adopting the thermal radiation coating for the PV module fabrication, the module efficiency was easily improved.

\section{Summary}

Single crystalline silicon PV modules (area: 1200 $\mathrm{mm} \times 527 \mathrm{~mm}$ ) were prepared and evaluated. A thermal radiation layer (Pelcool (R), PELNOX Ltd.) was coated on the back sheet of the PV module. The thickness of the layer was $30 \mu \mathrm{m}$. The thermal radiation layer consisted of acrylate resin and inorganic fillers. The fillers were selected to radiate the heat, particularly in the temperature range from 40 to $100^{\circ} \mathrm{C}$, which is the main range of operating temperature for the PV module. The thermal emissivity of the layer is 0.95 . In order to detect the temperature of the $\mathrm{PV}$ module $\left(\mathrm{T}_{\mathrm{mod}}\right)$, temperature sensors (Pt100) were set on the back surface of the PV modules. The temperature of the PV module with the thermal radiation coating was lower than that of the PV module without the thermal radiation coating. $V_{\text {oc }}$ of the $\mathrm{PV}$ module with the thermal radiation coating was $0.1 \mathrm{~V}$ higher than that of the module without the coating during the test period. The operating temperature range of the PV module with the thermal radiation coating was decreased by $2 \sim 3^{\circ} \mathrm{C}$. By adopting the thermal radiation coating, the module efficiency was easily improved. A new simple coating technology for handling heat radiation was developed. By adopting the thermal radiation coating for the $\mathrm{PV}$ module fabrication, the module efficiency was easily improved.

\section{References}

1. K. Nishioka, T. Hatayama, Y. Uraoka, T. Fuyuki, R. Hagihara, M. Watanabe, Solar Energy Materials and Solar Cells 75, 665 (2003)

2. K. Nishioka, N. Sakitani, K. Kurobe, Y. Yamamoto, Y. Ishikawa, Y. Uraoka, T. Fuyuki, Jpn. J. Appl. Phys. 42, 7175 (2003)

3. K. Nishioka, T. Takamoto, T. Agui, M. Kaneiwa, Y. Uraoka, T. Fuyuki, Solar Energy Materials and Solar Cells 85, 429 (2005)

4. K. Nishioka, T. Takamoto, T. Agui, M. Kaneiwa, Y. Uraoka, T. Fuyuki, Solar Energy Materials and Solar Cells 90, 57 (2006)

5. Kensuke Nishioka, Tsuyoshi Sueto, Masaki Uchida, Yasuyuki Ota, Journal of Electronic Materials 39, 704 (2010)

6. Kensuke Nishioka, Yasuyuki Ota, Kazuyuki Tamura, Kenji Araki, Surface and Coatings Technology 215, 472 (2013)

7. Yasuyuki Ota, Tsuyoshi Sueto, Hirokazu Nagai, Kenji Araki, Kensuke Nishioka, Jpn. J. Appl. Phys. 52, 04CR03 (2013)

8. K. Nomura, Y. Ota, T. Minemoto, K. Nishioka, ACTA PHYSICA POLONICA A 125, 1021 (2014) 
9. Kei Nomura, Yasuyuki Ota, Takashi Minemoto, Kensuke Nishioka, physica status solidi (c) 11, 1427 (2014)

10. Yasuyuki Ota, Hirokazu Nagai, Kenji Araki, Kensuke Nishioka, Jpn. J. Appl. Phys. 53, 122301 (2014)

11. Yuya Sakurada, Yasuyuki Ota, Kensuke Nishioka, Jpn. J. Appl. Phys. 50, 04DP13 (2011)
12. S. M. Sze, Physics of Semiconductor Devices (WileyInterscience Publication, 1981)

13. P. Antognetti and G. Massobrio, Semiconductor Device Modeling with SPICE (McGraw-Hill, 1988)

14. A. L. Fahrenbruch and R. H. Bube, Fundamentals of Solar Cells (Acadmic Press, Inc., 1983) 